\title{
Vascular aging and hemodynamic stability in the intraoperative period
}

\author{
Ferrante S. Gragasin ${ }^{1,2,3,4}{ }^{* \dagger}$, Stephane L. Bourque $e^{3,4,5 \dagger}$ and Sandra T. Davidge $e^{2,3,4,5}$ \\ ${ }^{1}$ Department of Anesthesiology and Pain Medicine, University of Alberta, Edmonton, AB, Canada \\ ${ }^{2}$ Department of Physiology, University of Alberta, Edmonton, AB, Canada \\ ${ }^{3}$ Cardiovascular Research Centre, University of Alberta, Edmonton, AB, Canada \\ ${ }^{4}$ Women and Children's Health Research Institute, University of Alberta, Edmonton, AB, Canada \\ ${ }^{5}$ Department of Obstetrics and Gynecology, University of Alberta, Edmonton, AB, Canada
}

\section{Edited by:}

Elisabet Vila, Autonomous University

of Barcelona, Spain

Reviewed by:

Akira Nishiyama, Kagawa University

Medical School, Japan

Shenyuan Zhang, Texas A\&M

University, USA

${ }^{*}$ Correspondence:

Ferrante S. Gragasin, Department of

Anesthesiology and Pain Medicine,

University of Alberta, Edmonton, $A B$,

Canada T6G 2 G3.

e-mail: gragasin@ualberta.ca

${ }^{\dagger}$ Ferrante S. Gragasin and

Stephane L. Bourque have

contributed equally to this work.
The proportion of elderly people in the population is steadily increasing, and the inevitable consequence is that this subpopulation is more frequently represented in common medical procedures and surgeries. Understanding the circulatory changes that accompany the aging process is therefore becoming increasingly timely and relevant. In this short review, we discuss aspects of vascular control in aging that are particularly relevant in the maintenance of intraoperative hemodynamic stability. We subsequently review the effects of certain notable anesthetic agents with respect to the aging vasculature.

Keywords: aging, anesthesia, vascular, hemodynamics, intraoperative

\section{INTRODUCTION}

The percentage of the population over the age of 65 is steadily increasing and is expected to continue in the foreseeable future (United-Nations, 2002), with people over the age of 80 now among the fastest growing subset of the population (Jarad, 2011). Currently, cardiovascular diseases (CVDs) are the most common cause of death among elderly patients in the Western world, accounting for more than $40 \%$ of all mortalities among people aged $65-74$, and $60 \%$ of people 85 years and older (Ungvari et al., 2010). Moreover, almost $70 \%$ of the population over the age of 70 has some degree of hypertension, which reflects the fact that blood pressure increases with age (Pedelty and Gorelick, 2008; Wills et al., 2011).

Despite the increased risk of CVD associated with aging, evidence indicates that health among the elderly population is improving, as illustrated by falling rates of ischemic heart disease, heart failure, and cerebrovascular disease among people over the age of 80 (National Heart, Lung and Blood Institute, 2006; Perls, 2009). The inevitable consequence of increasing life expectancy is that the aging population constitutes a greater proportion of patients undergoing medical treatments and presenting for surgery.

Since the elderly are associated with a higher incidence of disease and concurrent use of medications, intraoperative management of these patients can be challenging. For example, diabetes and hypertension are highly prevalent in this population and are known to impact various aspects of circulatory function. Medications such as beta blockers and angiotensin converting enzyme (ACE) inhibitors are commonly used in this age group, and the resultant drug interactions may also compromise hemodynamic stability and lead to untoward events. Even in the absence of these complicating factors, elderly patients are intrinsically more susceptible to the circulatory effects of anesthetic agents and other cardiovascular stressors due to the progressive structural and functional changes in the circulation that invariably occur with aging.

Due to increasing life expectancies in an ever-growing elderly population, studies pertaining to the circulatory changes in these patients are becoming increasingly timely and relevant. The focus of the present review is to consolidate the available information on aging as it pertains to vascular function and the intraoperative maintenance of hemodynamic stability in the elderly patient. Thus, rather than focusing on the mechanisms of aging that leads to progressive deterioration of circulatory function over a long period of time, we discuss aspects of the aging vasculature that are more relevant in the acute regulation of blood pressure - an important aspect in the intraoperative setting. We subsequently discuss the vascular effects of certain notable anesthetic agents, and where evidence is available, discuss some of the mechanisms underlying their effects. For more detailed reviews on the progressive vascular changes that occur with aging, see the following references: Seals et al. (2006), Mitchell (2008), Lekontseva et al. (2010), as well as those included in this issue of Frontiers in Physiology.

\section{HEMODYNAMIC INSTABILITY AND AGING}

One of the greatest challenges in intraoperative care for elderly patients is the maintenance of stable hemodynamic parameters. In particular, prevention of hypotension resulting in reduced end-organ perfusion is a primary concern. Elderly patients are 
more prone to developing hypotension in general (Johnson et al., 1965; Caird et al., 1973; Lipsitz et al., 1983; Shannon et al., 1986), but this may be exacerbated in surgery due to the fact that many anesthetic agents are, by nature, hypotensive-inducing. Hypoperfusion may be particularly harmful in elderly patients for several reasons. First, organs in elderly patients are accustomed to perfusion at higher pressures (Hoffman et al., 1981; Harrison et al., 1988; Tomanek, 1990); thus, in a patient with ischemic heart disease and long-standing hypertension, a decrease in blood pressure intraoperatively toward the "low-normal range" of healthy adults may actually be detrimental. Second, due to an age-associated decline in function, organs in the elderly appear more susceptible to loss of perfusion (Corcoran and Hillyard, 2011).

Given the prevalence of hypertension in the elderly population, it is perhaps counterintuitive that these patients are more susceptible to intraoperative hypotension (Reich et al., 2005). This hemodynamic "instability" stems from multiple factors acting in concert. First, the circulation in elderly patients is highly dependent on preload, such that alterations in vascular tone can have a large influence on cardiac output and end-organ perfusion (Corcoran and Hillyard, 2011). Second, evidence indicates that "physiologic reserve" declines with age (Lipsitz, 2004). Physiologic reserve broadly refers to a system's capacity to cope with homeostatic perturbations. In the context of acute blood pressure regulation, changes from the operating setpoint are buffered by two principal mechanisms: (1) baroreceptor reflex, which modulates autonomic nervous system activity; and (2) vascular responsiveness to shear stress, which is coupled to endothelial nitric oxide (NO) production (Park, 2002). Both baroreceptor capacity to buffer acute blood pressure changes and shear stress-induced production of NO are markedly attenuated in elderly patients (Mancia et al., 1991), resulting in a diminished capacity to cope with alterations in the blood pressure.

A third factor that contributes to the hemodynamic instability in the elderly is the downregulation of vasodilatory mechanisms (e.g., NO, prostaglandins) and concomitant upregulation of vascular constrictor mechanisms [endothelin (ET)-1, sympathetic nervous system (SNS) stimulation, renin-angiotensin system (RAS) activity]. The sudden removal of these vasoconstrictor signaling mechanisms by anesthetic agents (see below) may contribute to profound and prolonged hypotension. A case in point is the increased tonic SNS activity that occurs with aging (Seals and Esler, 2000). The consequences of this increased SNS activity are several-fold, but perhaps the most important implications are that (1) there is a greater autonomic support of arterial pressure in elderly patients compared to young patients (Jones et al., 2001), and (2) there is reduced responsiveness of alpha and beta receptors to further increases in catecholamine release (Mack, 2004), which may implicate receptor downregulation and post-receptor desensitization mechanisms (Xiao and Lakatta, 1992; Pilotti et al., 2004). Iatrogenic removal of this sympathetic "overstimulation" may therefore result in an exaggerated reduction in vascular tone, due to the increased reliance of peripheral vascular resistance on autonomic stimulation, thereby resulting in hypotension. Moreover, there is a compounding effect of reduced baroreceptor sensitivity which results in reduced sympathetic discharge (McConnell et al., 2009), coupled with reduced peripheral tissue responsiveness to released catecholamines (Ramos Macias et al., 1992; Sugiyama et al., 1996; Davy et al., 1998; Dinenno et al., 2001). In all, the elderly circulatory system has a significantly reduced capacity to cope with hemodynamic disturbances, particularly in the case when SNS activity is reduced.

\section{VASCULAR CHANGES ASSOCIATED WITH AGING AND EFFECTS OF ANESTHESIA: SPECIFIC AGENTS}

Anesthetics can influence hemodynamic stability directly by altering cardiac function, vascular reactivity, or affecting cardiovascular reflexes (Mallow et al., 1976; Westenskow et al., 1978; Bennett and Stanley, 1979; Waxman et al., 1980; Brismar et al., 1982; Fairfield et al., 1991). Because cardiac and vascular function are in many ways compromised with aging, the circulatory effects of anesthetics are exacerbated in the elderly (Tokics et al., 1985). Given the emphasis of the present review, we focus on the vascular effects of two primary classes of general anesthetics: inhalational and intravenous. It is also noteworthy that due to changes in pharmacokinetics, elderly patients tend to be more sensitive to the neurological effects of anesthetic agents. Although not discussed herein, it is possible that the circulatory effects of anesthetic agents may also be exacerbated in the elderly due to greater distribution to the brain, particularly if greater concentrations are achieved in the vasoregulatory centers; for information on these aspects of anesthetic agents in the aging population, see the following reviews (Kalker et al., 1991; Shafer, 2000; Kruijt Spanjer et al., 2011).

\section{INHALATIONAL ANESTHETICS}

While many of the vascular effects of anesthetic agents have been well-characterized in young patients and animals, relatively few studies have been done in the elderly or in animal models of aging. Inhalational anesthetic agents such as sevoflurane, isoflurane, and desflurane are widely acknowledged to cause greater hypotension in elderly patients than in young patients, albeit the scientific studies supporting this observation are generally lacking (Ebert, 2002). The principal cause of hypotension appears to implicate a loss vascular tone and reduction in total peripheral resistance (Lynch, 1986; Housmans and Murat, 1988; Pagel et al., 1991, 1993; Kikura and Ikeda, 1993), although the specific mechanisms are not clear. There is evidence that inhalational anesthetic agents decrease SNS activity, resulting in reduced vascular tone and diminished baroreceptor responsiveness in the wake of blood pressure fluctuations (Seagard et al., 1984; Tanaka et al., 1996). This is important because sudden decreases in SNS activity may cause excessive and prolonged vasodilation in the elderly, as described above. Yu et al. (2004) have also shown that inhalational anesthetics may decrease vascular tone through inhibition of the RAS, which is known to be upregulated in aging (Baruch, 2004; Diz, 2008). Given that angiotensin II is a strong vasoconstrictor and may lead to increased vascular tone, it is tempting to speculate that the sudden withdrawal of this system may produce a profound hypotension, analogous to the situation involving the SNS, as described above. However, evidence that directly implicates the RAS in this exaggerated hypotensive effect is presently lacking.

Inhalational anesthetics have also been shown to have direct vasodilatory effects on the vasculature, which may be implicated in the exaggerated effects in the elderly. In isolated vessels of several 
species, inhalational anesthetics mitigate the contractile responses to potassium chloride or norepinephrine; this effect was observed whether the endothelium was intact or not (Akata, 2007), suggesting a direct effect on vascular smooth muscle. Indeed, studies have shown that many such anesthetic agents influence calcium mobilization and sensitization (Tsuneyoshi et al., 2003; Akata, 2007) as well as potassium channel function (Tanaka et al., 2007) in vascular smooth muscle cells, with corresponding changes in vessel contractility. Given the importance of calcium channels and potassium channels in vascular tone, direct actions on these targets could potentially influence vascular responses to anesthetics in aging patients, although little information is available on the age-related changes with ion channels in the vasculature. There is evidence for diminished expression of large-conductance calciumactivated potassium channels in aging in both rodents and humans (Marijic et al., 2001; Toro et al., 2002), although their contribution to the vascular effects of inhalational anesthetic agents in aging is not currently known.

Inhalational anesthetics also have vasodilatory-promoting effects on endothelial function. Isoflurane has been shown to decrease ET-1 production (Boillot et al., 1995), which may have a profound effect in the elderly population given the increased ET-1 contribution to vascular tone with age (Stauffer et al., 2008; Goel et al., 2010). Inhalational anesthetics could also cause excessive vasodilation in the elderly via an antioxidant effect. While these agents do not appear to have intrinsic antioxidant effects per se, certain agents such as isoflurane and sevoflurane have been shown to increase endogenous antioxidant enzyme activity (Yang et al., 2011; Crystal et al., 2012), which may have a role in decreasing vascular tone. Indeed, in aging patients, a progressive increase in reactive oxygen species production is a well-defined etiological mechanism of vascular dysfunction and increased vasoconstriction (Herrera et al., 2010; Ungvari et al., 2010).

Interestingly, in contrast to those aforementioned studies, inhalational anesthetics have also been shown to increase vascular responsiveness to norepinephrine and $\mathrm{KCl}$ in rat mesenteric arteries, an effect that is entirely dependent on an intact endothelium (Stone and Johns, 1989; Izumi et al., 2000, 2001; Yoshino et al., 2005). Similarly, several groups have shown that these agents also inhibit endothelial-dependent vasodilation (Muldoon et al., 1988; Toda et al., 1992; Uggeri et al., 1992; Yoshida and Okabe, 1992; Park et al., 1997). The mechanisms underlying this latter observation are not clear, although neither NO, endothelium-derived hyperpolarizing factor, prostaglandin $\mathrm{H}$ synthase, and lipoxygenase pathways, nor ET-1, angiotensin II, or serotonin receptors appear to be implicated; calcium, potassium, and sodium channels are obvious potential targets. Taken together, these studies demonstrate that anesthetic effects on the endothelium, are in part, vasoconstrictor in nature. Although puzzling, this apparent disparity may be reconciled by the fact that the net effect of an agent is the sum of all simultaneous effects on the vessel (Muldoon et al., 1988). Therefore, while the endothelial effects of anesthetics appears to be vasoconstrictor in nature, the net effect, taking into account the effects of inhaled anesthetics on smooth muscle function, SNS, RAS, and other local and humoral factors, is vasodilatory. Since elderly patients are known to have altered endothelial secretory profiles, it is tempting to speculate that the hypotensive effects of inhalational anesthetics stem, at least in part, from mitigated endothelial vasoconstrictor effects producing an overall enhanced vasodilation. Studies are needed to directly test this hypothesis.

\section{INTRAVENOUS ANESTHETICS Etomidate}

In vessels from young rats, etomidate causes direct vasodilation ex vivo (Bazin et al., 1998), involving increased vasodilator prostaglandins (Asher et al., 1992) and decreased ET-1 production (Hayashi et al., 1999). However, in vivo, administration of etomidate has little effect on blood pressure in young patients; in fact, its hemodynamic stability during induction of general anesthesia make it a preferred agent in many clinical scenarios (Gooding and Corssen, 1977; Criado et al., 1980). The hemodynamic stability of etomidate appears to stem from a lack of inhibition of SNS function (Ebert et al., 1992; Robinson et al., 1997). Thus, despite causing direct vasodilation, hemodynamic perturbations are transient and easily corrected by baroreceptor stimulation of heart rate and contractility. However, when administered to elderly patients, etomidate causes a $20-30 \%$ decrease in blood pressure (Larsen et al., 1988). This hypotensive effect is not well understood, although recent studies have provided insights into its mechanism. The reason may be due in part to the interaction between etomidate and adrenoceptor signaling. Etomidate enhances norepinephrineinduced constriction in mesenteric resistance arteries in young rats, resulting in increased vascular tone; this effect appears to be lost in aged rats (Shirozu et al., 2009). The authors of this study suggested that hypotension with etomidate in aged patients is not due to direct actions on the vasculature but rather due to interference with norepinephrine-induced vasoconstriction. Interestingly, Ebert et al. (1992) demonstrated that etomidate does not reduce overall release of catecholamines from sympathetic nerve terminals, suggesting that the majority of the blood pressure-lowering effects in the elderly may stem from altering the adrenoceptor responsiveness to catecholamines. Thus, despite increased NE levels in aging patients, etomidate-induced decrease in adrenoceptor responsiveness results in a more profound vasodilatory effect.

Etomidate is also known to cause adrenocortical suppression (Allolio et al., 1985; Lamberts et al., 1987), resulting in diminished cortisol release which can be problematic in certain patients (e.g., septic patients). Cortisol increases blood pressure principally by increasing sensitivity of the vasculature to catecholamines. Thus, etomidate-induced reduction in cortisol production may also play a role in causing hypotension in the intraoperative period, again making elderly patients more susceptible to this effect due to the progressive loss of catecholamine responsiveness with aging. This is supported by a recent case report of an elderly patient given a single dose of etomidate causing refractory hypotension that was only reversible with cortisol administration (Lundy et al., 2007). It is noteworthy that this mechanism is likely in addition to that described by Shirozu et al. (2009) since those experiments were done in isolated vessels.

\section{Propofol}

It was recently reported that the use of propofol over other general anesthetics, as well as age of the patient, are independent predictors 
of clinically significant hypotension in patients undergoing general anesthesia (Reich et al., 2005). The majority of hypotensive effects of propofol appear to occur via reduced systemic vascular resistance. Part of this effect may stem from the fact that propofol, in contrast to etomidate, diminishes SNS function (Robinson et al., 1997), which may result in vasodilation. Moreover, loss of SNS activity results in decreased compensatory heart rate and contractility in the wake of hypotension, may be an important contributor to its hypotensive effects in the elderly, as described above. Propofol has also been shown to cause direct relaxation in several vascular beds, [e.g., aorta in rat (Boillot et al., 1999), coronary artery in the pig (Park et al., 1995), and mesenteric arteries in humans and rats (Moreno et al., 1997; Yamazaki et al., 2002)], although studies by Yamashita et al. (1999) and Kamitani et al. (1995) have shown opposite effects in rabbits, which may suggest species differences. In young animals, propofol increases NO production in isolated endothelial cells concomitant with decreased ET-1 release from the endothelium (Cheng et al., 2009). Tanabe et al. (1998) also showed that propofol inhibits ET-1 signaling in vascular smooth muscle. Given the role of diminished NO and increased ET- 1 as important mechanisms in vascular aging, it seems plausible that these mediators may be implicated in the exaggerated hypotensive effects in elderly patients.

In our studies, we demonstrated that propofol causes enhanced mesenteric artery relaxation in aged rats when compared to young, and this effect was attributed to increased NO bioavailability (Gragasin and Davidge, 2009). We also demonstrated that the combination of antioxidant enzymes superoxide dismutase and catalase enhance vasodilation to acetylcholine similar to propofol in aged rats (Gragasin and Davidge, 2009). On the basis of these studies, we suggested that propofol may exert part of its vasodilatory effects via intrinsic antioxidant effects (Ansley et al., 1998), since it is structurally similar to $\alpha$-tocopherol (vitamin E). Thus, we speculate that the vasodilatory effect may be more pronounced because aging vessels have increased oxidative stress. These data may also suggest that the use of NO donors to treat acute hypertensive crises intraoperatively may be harmful in elderly patients anesthetized with propofol. Indeed, it is already known that elderly patients have an increased sensitivity to nitroglycerin causing hypotension (Cahalan et al., 1992), and the presence of propofol may cause an unwanted synergistic blood pressure-lowering effect.

More recently, we investigated the effects of propofol in aged animals treated with the ACE inhibitor captopril. ACE inhibitors

\section{REFERENCES}

Akata, T. (2007). General anesthetics and vascular smooth muscle: direct actions of general anesthetics on cellular mechanisms regulating vascular tone. Anesthesiology 106, 365-391.

Allolio, B., Dorr, H., Stuttmann, R., Knorr, D., Engelhardt, D., and Winkelmann, W. (1985). Effect of a single bolus of etomidate upon eight major corticosteroid hormones and plasma ACTH. Clin. Endocrinol. (Oxf.) 22, 281-286.

are commonly prescribed medications for blood pressure control in elderly patients, and it is well documented that these treated patients exhibit greater hypotension under general anesthesia (Bertrand et al., 2001; Comfere et al., 2005; Kheterpal et al., 2008). It has been suggested that there may be an interaction between ACE inhibitors and propofol which causes severe hypotension (Malinowska-Zaprzalka et al., 2005). In an aging rodent model, chronic treatment with captopril increases endothelial-dependent vasodilation in the presence of propofol (unpublished data). Interestingly, NO was not responsible for the differential response observed between control and captopril-treated rats (unpublished data); thus there may be alterations in other vasodilating mechanisms such as endothelial-derived hyperpolarizing factor (Hutri-Kahonen et al., 1997; Goto et al., 2000). The caveat is that isolated vessels may not recapitulate in vivo vascular responses, and therefore further investigation using integrated, whole-animal approaches are needed to identify the mechanisms underlying this enhanced relaxation.

\section{CONCLUSION}

Aging is associated with a multitude of changes at the vascular level, including structural changes, enhanced oxidative stress, and altered secretory profiles of vasoconstrictor and vasodilators. Anesthetic agents may acutely alter this balance leading to excessive and unwanted vasodilation in the elderly, and elucidating the underlying mechanisms dictating vascular function and its changes with age are therefore crucial. Moreover, given that elderly patients often have existing co-morbidities, additional studies are needed to elucidate the mechanisms of anesthetic-induced changes in hemodynamics in the presence of overt disease, such as hypertension, diabetes, chronic kidney disease, or more surreptitious conditions associated with aging, such as nutritional deficiencies (e.g., iron deficiency), which may have additional effects on vascular function. From a clinical perspective, the Anesthesiologist is tasked with making important decisions about drug use in elderly patients, considering factors such as patient safety, neurological recovery, and drug availability. Gaining further knowledge of the mechanisms of action of anesthetic agents at the vascular level as well in intact animal models can potentially be translated to the bedside, possibly changing clinical practice by enhancing management of circulatory health in the elderly during the intraoperative period.

Clin. Hypertens. (Greenwich) 6, 249-255.

Bazin, J. E., Dureuil, B., Danialou, G., Vicaut, E., Aubier, M., Desmonts, J. M., and Boczkowski, J. (1998). Effects of etomidate, propofol and thiopental anaesthesia on arteriolar tone in the rat diaphragm. Br. J. Anaesth. 81, 430-435.

Bennett, G. M., and Stanley, T. H. (1979). Cardiovascular effects of fentanyl during enflurane anesthesia in man. Anesth. Analg. 58, 179-182. Bertrand, M., Godet, G., Meersschaert, K., Brun, L., Salcedo, E., and Coriat,
P. (2001). Should the angiotensin II antagonists be discontinued before surgery? Anesth. Analg. 92, 26-30.

Boillot, A., Laurant, P., Berthelot, A., and Barale, F. (1999). Effects of propofol on vascular reactivity in isolated aortae from normotensive and spontaneously hypertensive rats. $\mathrm{Br}$. J. Anaesth. 83, 622-629.

Boillot, A., Vallet, B., Marty, J., Auclerc, A., and Barale, F. (1995). Effects of halothane, enflurane and isoflurane on contraction of rat aorta induced by endothelin-1. Br. J. Anaesth. 75, 761-767. 
Brismar, B., Hedenstierna, G., Lundh, R., and Tokics, L. (1982). Oxygen uptake, plasma catecholamines and cardiac output during neuroleptnitrous oxide and halothane anaesthesias. Acta Anaesthesiol. Scand. 26, 541-549.

Cahalan, M. K., Hashimoto, Y., Aizawa, K., Verotta, D., Ionescu, P., Balea, M., Eger, E. I. II, Benet, L. Z., Ehrenfeld, W. K., Goldstone, J., Reilly, L. M., Stoney, R. J., and Sheiner, L. B. (1992). Elderly, conscious patients have an accentuated hypotensive response to nitroglycerin. Anesthesiology 77, 646-655.

Caird, F. I., Andrews, G. R., and Kennedy, R. D. (1973). Effect of posture on blood pressure in the elderly. Br. Heart J. 35, 527-530.

Cheng, T. H., Chen, J. J., Chen, C. H., and Wong, K. L. (2009). Effects of propofol on cyclic straininduced endothelin-1 expression in human umbilical vein endothelial cells. Anesthesiology 110, 74-80.

Comfere, T., Sprung, J., Kumar, M. M., Draper, M., Wilson, D. P., Williams, B. A., Danielson, D. R., Liedl, L., and Warner, D. O. (2005). Angiotensin system inhibitors in a general surgical population. Anesth. Analg. 100, 636-644, table of contents.

Corcoran, T. B., and Hillyard, S. (2011). Cardiopulmonary aspects of anaesthesia for the elderly. Best Pract. Res. Clin. Anaesthesiol. 25, 329-354

Criado, A., Maseda, J., Antón, S., Gilsanz, F. J., and Avello, F. (1980). Cerebral activity during anesthesia induction with etomidate. Rev. Esp. Anestesiol. Reanim. 27, 15-20.

Crystal, G. J., Malik, G., Yoon, S. H., and Kim, S. J. (2012). Isoflurane late preconditioning against myocardial stunning is associated with enhanced antioxidant defenses. Acta Anaesthesiol. Scand. 56, 39-47.

Davy, K. P., Seals, D. R., and Tanaka, H. (1998). Augmented cardiopulmonary and integrative sympathetic baroreflexes but attenuated peripheral vasoconstriction with age. Hypertension 32, 298-304.

Dinenno, F. A., Tanaka, H., Stauffer, B. L., and Seals, D. R. (2001). Reductions in basal limb blood flow and vascular conductance with human ageing: role for augmented alphaadrenergic vasoconstriction. J. Physiol. (Lond.) 536, 977-983.

Diz, D. I. (2008). Lewis K. Dahl memorial lecture: the renin-angiotensin system and aging. Hypertension 52, 37-43.

Ebert, T. J. (2002). "Physiology of the cardiovascular effects of general anesthesia in the elderly," in Syllabus on Geriatric Anesthesiology, American Society of Anesthesiologists. Available at: http://asatest.asahq.org/clinical/geri atrics/phy.htm

Ebert, T. J., Muzi, M., Berens, R., Goff, D., and Kampine, J. P. (1992). Sympathetic responses to induction of anesthesia in humans with propofol or etomidate. Anesthesiology 76, 725-733.

Fairfield, J. E., Dritsas, A., and Beale, R. J. (1991). Haemodynamic effects of propofol: induction with $2.5 \mathrm{mg}$ $\mathrm{kg}^{-1}$. Br. J. Anaesth. 67, 618-620.

Goel, A., Su, B., Flavahan, S., Lowenstein, C. J., Berkowitz, D. E., and Flavahan, N. A. (2010). Increased endothelial exocytosis and generation of endothelin-1 contributes to constriction of aged arteries. Circ. Res. 107, 242-251.

Gooding, J. M., and Corssen, G. (1977). Effect of etomidate on the cardiovascular system. Anesth. Analg. 56, 717-719.

Goto, K., Fujii, K., Onaka, U., Abe, I., and Fujishima, M. (2000). Angiotensinconverting enzyme inhibitor prevents age-related endothelial dysfunction. Hypertension 36, 581-587. Gragasin, F. S., and Davidge, S. T. (2009). The effects of propofol on vascular function in mesenteric arteries of the aging rat. Am. J. Physiol. Heart Circ. Physiol. 297, H466-H474.

Harrison, D. G., Florentine, M. S., Brooks, L. A., Cooper, S. M., and Marcus, M. L. (1988). The effect of hypertension and left ventricular hypertrophy on the lower range of coronary autoregulation. Circulation 77, 1108-1115.

Hayashi, Y., Minamino, N., Isumi, Y., Kangawa, K., Kuro, M., and Matsuo, H. (1999). Effects of thiopental, ketamine, etomidate, propofol and midazolam on the production of adrenomedullin and endothelin-1 in vascular smooth muscle cells. Res. Commun. Mol. Pathol. Pharmacol. 103, 325-331.

Herrera, M. D., Mingorance, C., Rodríguez-Rodríguez, R., and Alvarez de Sotomayor, M. (2010). Endothelial dysfunction and aging: an update. Ageing Res. Rev. 9, 142-152.

Hoffman, W. E., Albrecht, R. F., and Miletich, D. J. (1981). The influence of aging and hypertension on cerebral autoregulation. Brain Res. 214, 196-199.

Housmans, P. R., and Murat, I. (1988). Comparative effects of halothane, enflurane, and isoflurane at equipotent anesthetic concentrations on isolated ventricular myocardium of the ferret. I. Contractility. Anesthesiology 69, 451-463.

Hutri-Kahonen, N., Kahonen, M., Tolvanen, J. P., Wu, X., Sallinen, K., and Pörsti, I. (1997). Ramipril therapy improves arterial dilation in experimental hypertension. Cardiovasc. Res. 33, 188-195.

Izumi, K., Akata, T., and Takahashi, S. (2000). The action of sevoflurane on vascular smooth muscle of isolated mesenteric resistance arteries (part 1): role of endothelium. Anesthesiology 92, 1426-1440.

Izumi, K., Akata, T., and Takahashi, S. (2001). Role of endothelium in the action of isoflurane on vascular smooth muscle of isolated mesenteric resistance arteries. Anesthesiology 95, 990-998.

Jarad, N. (2011). The size of current and future problems. Chron. Respir. Dis. 8, 141-142.

Johnson, R. H., Smith, A. C., Spalding, J. M., and Wollner, L. (1965). Effect of posture on blood-pressure in elderly patients. Lancet 1, 731-733.

Jones, P. P., Shapiro, L. F., Keisling, G. A. Jordan, J., Shannon, J. R., Quaife, R. A., and Seals, D. R. (2001). Altered autonomic support of arterial blood pressure with age in healthy men. Circulation 104, 2424-2429.

Kalker, U., Leppek, S., and Peters, M. (1991). Screening for cardiovascular risk factors in public screening programs: are target groups being reached? Offentl. Gesundheitswes. 53, 604-605.

Kamitani, K., Yamazaki, M., Yukitaka, M., Ito, Y., and Momose, Y. (1995). Effects of propofol on isolated rabbit mesenteric arteries and veins. $\mathrm{Br}$. J. Anaesth. 75, 457-461.

Kheterpal, S., Khodaparast, O., Shanks, A., O'Reilly, M., and Tremper, K. K. (2008). Chronic angiotensinconverting enzyme inhibitor or angiotensin receptor blocker therapy combined with diuretic therapy is associated with increased episodes of hypotension in noncardiac surgery. J. Cardiothorac. Vasc. Anesth. 22, 180-186.

Kikura, M., and Ikeda, K. (1993). Comparison of effects of sevoflurane/nitrous oxide and enflurane/nitrous oxide on myocardial contractility in humans. load-independent and noninvasive assessment with transesophageal echocardiography. Anesthesiology 79, 235-243.

Kruijt Spanjer, M. R., Bakker, N. A., and Absalom, A. R. (2011). Pharmacology in the elderly and newer anaesthesia drugs. Best Pract. Res. Clin. Anaesthesiol. 25, 355-365.
Lamberts, S. W., Bons, E. G., Bruining, H. A., and de Jong, F. H. (1987). Differential effects of the imidazole derivatives etomidate, ketoconazole and miconazole and of metyrapone on the secretion of cortisol and its precursors by human adrenocortical cells. J. Pharmacol. Exp. Ther. 240, 259-264.

Larsen, R., Rathgeber, J., Bagdahn, A., Lange, H., and Rieke, H. (1988). Effects of propofol on cardiovascular dynamics and coronary blood flow in geriatric patients. a comparison with etomidate. Anaesthesia 43, 25-31.

Lekontseva, O., Chakrabarti, S., and Davidge, S. T. (2010). Endothelin in the female vasculature: a role in aging? Am. J. Physiol. Regul. Integr. Comp. Physiol. 298, R509-R516.

Lipsitz, L. A. (2004). Physiological complexity, aging, and the path to frailty. Sci. Aging Knowledge Environ. 2004, pe16.

Lipsitz, L. A., Nyquist, R. P. J., Wei, J. Y., and Rowe, J. W. (1983). Postprandial reduction in blood pressure in the elderly. N. Engl. J. Med. 309 1255-1256.

Lundy, J. B., Slane, M. L., and Frizzi, J. D. (2007). Acute adrenal insufficiency after a single dose of etomidate. $J$. Intensive Care Med. 22, 111-117.

Lynch, C. III. (1986). Differential depression of myocardial contractility by halothane and isoflurane in vitro. Anesthesiology 64, 620-631.

Mack, G. W. (2004). Hypothalamic control of body temperature: insights from the past. J. Appl. Physiol. 97, 1593-1594.

Malinowska-Zaprzalka, M., Wojewodzka, M., Dryl, D., Grabowska, S. Z., and Chabielska, E. (2005) Hemodynamic effect of propofol in enalapril-treated hypertensive patients during induction of general anesthesia. Pharmacol. Rep. 57, 675-678.

Mallow, J. E., White, R. D., Cucchiara, R. F., and Tarhan, S. (1976). Hemodynamic effects of isoflurane and halothane in patients with coronary artery disease. Anesth. Analg. 55, 135-138.

Mancia, G., Cleroux, J., Daffonchio, A., Ferrari, A. U., Giannattasio, C., and Grassi, G. (1991). Reflex control of circulation in the elderly. Cardiovasc. Drugs Ther. 4, 1223-1228.

Marijic, J., Li, Q., Song, M., Nishimaru, K., Stefani, E., and Toro, L. (2001). Decreased expression of voltageand $\mathrm{Ca} 2+-$ activated $\mathrm{K}+-$ channels in coronary smooth muscle during aging. Circ. Res. 88, 210-216. 
McConnell, K., Somers, V. K., Kimball, T., Daniels, S., VanDyke, R., Fenchel, M., Cohen, A., Willging, P., Shamsuzzaman, A., and Amin, R. (2009). Baroreflex gain in children with obstructive sleep apnea. Am. J. Respir. Crit. Care Med. 180, $42-48$.

Mitchell, G. F. (2008). Effects of central arterial aging on the structure and function of the peripheral vasculature: implications for endorgan damage. J. Appl. Physiol. 105, 1652-1660.

Moreno, L., Martinez-Cuesta, M. A., Muedra, V., Beltrán, B., and Esplugues, J. (1997). Role of the endothelium in the relaxation induced by propofol and thiopental in isolated arteries from man. J. Pharm. Pharmacol. 49, 430-432.

Muldoon, S. M., Hart, J. L., Bowen, K. A., and Freas, W. (1988). Attenuation of endothelium-mediated vasodilation by halothane. Anesthesiology 68, 31-37.

National Heart, Lung and Blood Institute. (2006). Incidence and Prevalence: 2006 Chartbook on Cardiovascular and Lung Diseases. Available at: http://www.nhlbi.nih.gov/ resources/docs/cht-book_ip.htm. 2011

Pagel, P. S., Kampine, J. P., Schmeling, W. T., and Warltier, D. C. (1991). Influence of volatile anesthetics on myocardial contractility in vivo: desflurane versus isoflurane. Anesthesiology 74, 900-907.

Pagel, P. S., Kampine, J. P., Schmeling, W. T., and Warltier, D. C. (1993). Evaluation of myocardial contractility in the chronically instrumented dog with intact autonomic nervous system function: effects of desflurane and isoflurane. Acta Anaesthesiol. Scand. 37, 203-210.

Park, K. W. (2002). Cardiovascular effects of inhalational anesthetics. Int. Anesthesiol. Clin. 40, 1-14.

Park, K. W., Dai, H. B., Lowenstein, E., Darvish, A., and Sellke, F. W. (1997). Isoflurane and halothane attenuate endothelium-dependent vasodilation in rat coronary microvessels. Anesth. Analg. 84, 278-284.

Park, K. W., Dai, H. B., Lowenstein, E., and Sellke, F. W. (1995). Propofolassociated dilation of rat distal coronary arteries is mediated by multiple substances, including endotheliumderived nitric oxide. Anesth. Analg. 81, 1191-1196.

Pedelty, L., and Gorelick, P. B. (2008). Management of hypertension and cerebrovascular disease in the elderly. Am. J. Med. 121, S23-S31.
Perls, T. (2009). Health and disease in people over 85. BMJ 339, b4715.

Pilotti, M., Chodorow, M., and Thornton, K. C. (2004). Asymmetric interference effects in fragment completion: the consequences of recognition failures and successes. Am. J. Psychol. 117, 565-578.

Ramos Macias, A., de Miguel Martinez, I., Martín Sánchez, A. M., Gómez González, J. L., and Martín Galán, A. (1992). The incorporation of acyclovir into the treatment of peripheral paralysis: a study of 45 cases. Acta Otorrinolaringol. Esp. 43, 117-120.

Reich, D. L., Hossain, S., Krol, M., Baez, B., Patel, P., Bernstein, A., and Bodian, C. A. (2005). Predictors of hypotension after induction of general anesthesia. Anesth. Analg. 101, 622-628, table of contents.

Robinson, B. J., Ebert, T. J., O’Brien, T. J., Colinco, M. D., and Muzi, M. (1997). Mechanisms whereby propofol mediates peripheral vasodilation in humans. sympathoinhibition or direct vascular relaxation? Anesthesiology 86, 64-72.

Seagard, J. L., Hopp, F. A., Bosnjak, Z. J., Osborn, J. L., and Kampine, J. P. (1984). Sympathetic efferent nerve activity in conscious and isofluraneanesthetized dogs. Anesthesiology 61, 266-270.

Seals, D. R., and Esler, M. D. (2000). Human ageing and the sympathoadrenal system. J. Physiol. (Lond.) 528, 407-417.

Seals, D. R., Moreau, K. L., Gates, P. E., and Eskurza, I. (2006). Modulatory influences on ageing of the vasculature in healthy humans. Exp. Gerontol. 41, 501-507.

Shafer, S. L. (2000). The pharmacology of anesthetic drugs in elderly patients. Anesthesiol. Clin. North America 18, 1-29.

Shannon, R. P., Wei, J. Y., Rosa, R. M., Epstein, F. H., and Rowe, J. W. (1986). The effect of age and sodium depletion on cardiovascular response to orthostasis. Hypertension 8, 438-443.

Shirozu, K., Akata, T., Yoshino, J., Setoguchi, H., Morikawa, K., and Hoka, S. (2009). The mechanisms of the direct action of etomidate on vascular reactivity in rat mesenteric resistance arteries. Anesth. Analg. 108, 496-507.

Stauffer, B. L., Westby, C. M., and DeSouza, C. A. (2008). Endothelin-1, aging and hypertension. Curr. Opin. Cardiol. 23, 350-355.

Stone, D. J., and Johns, R. A. (1989). Endothelium-dependent effects of halothane, enflurane, and isoflurane on isolated rat aortic vascular rings. Anesthesiology 71, 126-132.

Sugiyama, Y., Matsukawa, T., Shamsuz zaman, A. S., Okada, H., Watanabe, T., and Mano, T. (1996). Delayed and diminished pressor response to muscle sympathetic nerve activity in the elderly. J. Appl. Physiol. 80, 869-875.

Tanabe, K., Kozawa, O., Kaida, T., Matsuno, H., Niwa, M., Ohta, S., Dohi, S., and Uematsu, T. (1998). Inhibitory effects of propofol on intracellular signaling by endothelin-1 in aortic smooth muscle cells. Anesthesiology 88, 452-460.

Tanaka, K., Kawano, T., Nakamura, A., Nazari, H., Kawahito, S., Oshita, S., Takahashi, A., and Nakaya, Y. (2007). Isoflurane activates sarcolemmal adenosine triphosphatesensitive potassium channels in vascular smooth muscle cells: a role for protein kinase A. Anesthesiology 106 984-991.

Tanaka, S., Tsuchida, H., Nakabayashi, K., Seki, S., and Namiki, A. (1996). The effects of sevoflurane, isoflurane, halothane, and enflurane on hemodynamic responses during an inhaled induction of anesthesia via a mask in humans. Anesth. Analg. 82, 821-826.

Toda, H., Nakamura, K., Hatano, Y., Nishiwada, M., Kakuyama, M., and Mori, K. (1992). Halothane and isoflurane inhibit endotheliumdependent relaxation elicited by acetylcholine. Anesth. Analg. 75, 198-203.

Tokics, L., Brismar, B., and Hedenstierna, G. (1985). Halothanerelaxant anaesthesia in elderly patients. Acta Anaesthesiol. Scand. 29, 303-308.

Tomanek, R. J. (1990). Response of the coronary vasculature to myocardial hypertrophy. J. Am. Coll. Cardiol. 15, 528-533.

Toro, L., Marijic, J., Nishimaru, K. Tanaka, Y., Song, M., and Stefani, E. (2002). Aging, ion channel expression, and vascular function. Vascul. Pharmacol. 38, 73-80.

Tsuneyoshi, I., Zhang, D., and Boyle, W. A. III. (2003). Ca2+- and myosin phosphorylation-independent relaxation by halothane in $\mathrm{K}+$ depolarized rat mesenteric arteries. Anesthesiology 99, 656-665.

Uggeri, M. J., Proctor, G. J., and Johns, R. A. (1992). Halothane, enflurane, and isoflurane attenuate both receptorand non-receptor-mediated EDRF production in rat thoracic aorta. Anesthesiology 76, 1012-1017.

Ungvari, Z., Kaley, G., de Cabo, R., Sonntag, W. E., and Csiszar, A. (2010). Mechanisms of vascular aging: new perspectives. J. Gerontol. A Biol. Sci. Med. Sci. 65, 1028-1041.

United-Nations. (2002). World Population Aging: 1950-2050. New York: Department of Economic and Social Affairs Population Division.

Waxman, K., Shoemaker, W. C., and Lippmann, M. (1980). Cardiovascular effects of anesthetic induction with ketamine. Anesth. Analg. 59, 355-358.

Westenskow, D. R., Jordan, W. S., Hodges, M. R., and Stanleym, T. H. (1978). Correlation of oxygen uptake and cardiovascular dynamics during $\mathrm{N} 2 \mathrm{O}$-fentanyl and N2Othiopental anesthesia in the dog. Anesth. Analg. 57, 37-41.

Wills, A. K., Lawlor, D. A., Matthews, F. E., Sayer, A. A., Bakra, E., BenShlomo, Y., Benzeval, M., Brunner, E., Cooper, R., Kivimaki, M., Kuh, D., Muniz-Terrera, G., and Hardy, R. (2011). Life course trajectories of systolic blood pressure using longitudinal data from eight UK cohorts. PLoS Med. 8, e1000440. doi:10.1371/journal.pmed.1000440

Xiao, R. P., and Lakatta, E. G. (1992). Deterioration of beta-adrenergic modulation of cardiovascular function with aging. Ann. N. Y. Acad. Sci. 673, 293-310.

Yamashita, A., Kajikuri, J., Ohashi, M., Kanmura, Y., and Itoh, T. (1999). Inhibitory effects of propofol on acetylcholine-induced, endothelium-dependent relaxation and prostacyclin synthesis in rabbit mesenteric resistance arteries. Anesthesiology 91, 1080-1089.

Yamazaki, M., Nagakawa, T., Deng, J., Wang, Q., Ye, R., Li, X., Hu, S., Dong, H., and Xiong, L. (2002). The effects of propofol on neural and endothelial control of in situ rat mesenteric vascular smooth muscle transmembrane potentials. Anesth. Analg. 94, 892-897, table of contents.

Yang, Q., Dong, H., Deng, J., Wang, Q., Ye, R., Li, X., Hu, S., Dong, H., and Xiong, L. (2011). Sevoflurane preconditioning induces neuroprotection through reactive oxygen species-mediated up-regulation of antioxidant enzymes in rats. Anesth. Analg. 112, 931-937.

Yoshida, K., and Okabe, E. (1992). Selective impairment of endotheliumdependent relaxation by sevoflurane: oxygen free radicals participation. Anesthesiology 76, 440-447.

Yoshino, J., Akata, T., Izumi, K., and Takahashi, S. (2005). Multiple actions of halothane on contractile response to noradrenaline in isolated mesenteric resistance arteries. 
Naunyn Schmiedebergs Arch. Pharmacol. 371, 500-515.

Yu, J., Tokinaga, Y., Ogawa, K., Iwahashi, S., and Hatano, Y. (2004). Sevoflurane inhibits angiotensin II-induced, protein kinase c-mediated but not $\mathrm{Ca} 2+$-elicited contraction of rat aortic smooth muscle. Anesthesiology $100,879-884$.
Conflict of Interest Statement: The authors declare that the research was conducted in the absence of any commercial or financial relationships that could be construed as a potential conflict of interest.

Received:26 January 2012; paper pending published: 15 February 2012; accepted: 14
March 2012; published online: 02 Apri 2012.

Citation: Gragasin FS, Bourque SL and Davidge ST (2012) Vascular aging and hemodynamic stability in the intraoperative period. Front. Physio. 3:74. doi 10.3389/fphys.2012.00074

This article was submitted to Frontiers in Vascular Physiology, a specialty of
Frontiers in Physiology. Copyright (c) 2012 Gragasin, Bourque and Davidge. This is an open-access article distributed under the terms of the Creative Commons Attribution Non Commercial License, which permits noncommercial use, distribution, and reproduction in other forums, provided the original authors and source are credited. 